\title{
Virological analysis of fatal influenza cases in the United Kingdom during the early wave of influenza in winter 2010/11
}

J Ellis (joanna.ellis@hpa.org.uk) ${ }^{1}$, M Galiano $^{1}$, R Pebody $^{1}$, A Lackenby $^{1}$, CI Thompson $^{1}$, A Bermingham ${ }^{1}$, E McLean $^{1}$, H Zhao $^{1}$, S Bolotin ${ }^{1}, 0$ Dar $^{1}$, J M Watson ${ }^{1}$, M Zambon $^{1}$

1. Health Protection Agency, Centre for Infections, London, United Kingdom

Citation style for this article:

Ellis J, Galiano M, Pebody R, Lackenby A, Thompson C, Bermingham A, McLean E, Zhao H, Bolotin S, Dar O, Watson JM, Zambon M. Virological analysis of fatal influenza cases in the United Kingdom during the early wave of influenza in winter 2010/11. Euro Surveill. 2011;16(1): pii=19760. Available online: http://www. eurosurveillance.org/ViewArticle.aspx?Articleld $=19760$

Article published on 6 January 2011

The 2010/11 winter influenza season is underway in the United Kingdom, with co-circulation of influenza $A\left(\mathrm{H}_{1} \mathrm{~N}_{1}\right) 2009$ (antigenically similar to the current 2010/11 vaccine strain), influenza B (mainly B/ Victoria/2/87 lineage, similar to the $2010 / 11$ vaccine strain) and a few sporadic influenza $\mathrm{A}\left(\mathrm{H}_{3} \mathrm{~N}_{2}\right)$ viruses. Clinical influenza activity has been increasing. Severe illness, resulting in hospitalisation and deaths, has occurred in children and young adults and has predominantly been associated with influenza $A\left(\mathrm{H}_{1} \mathrm{~N}_{1}\right)_{2009}$, but also influenza B viruses.

\section{Introduction}

The onset of this winter season in the northern hemisphere is associated with more uncertainty than usual about which influenza viruses are likely to circulate and predominate, given the varying proportions of different virus strains circulating in the southern hemisphere between June and September 2010 [1]. Notably, influenza $\mathrm{A}\left(\mathrm{H}_{3} \mathrm{~N}_{2}\right)$ predominated over influenza $A\left(\mathrm{H}_{1} \mathrm{~N}_{1}\right) 2009$ in several countries, e.g. South Africa and Chile. The second wave of the pandemic in the United Kingdom (UK) during the winter season of 2009/10 was almost exclusively associated with circulation of influenza $A\left(\mathrm{H}_{1} \mathrm{~N}_{1}\right)_{2009}$ [2]. Serological evaluation in the UK of population immunity to the pandemic strain after the second wave suggested that susceptibility was lowest in younger age groups ( $\$ 15$ years), with significant remaining susceptibility in the age group of 15-44 year-olds [3]. In view of the importance of children in the transmission of influenza $A\left(\mathrm{H}_{1} \mathrm{~N}_{1}\right)_{2009}$ [4], and the limited remaining susceptibility within this group, the

\section{FIGURE 1}

Royal College of General Practitioners influenza like illness consultation rates, England and Wales, current and past seasons

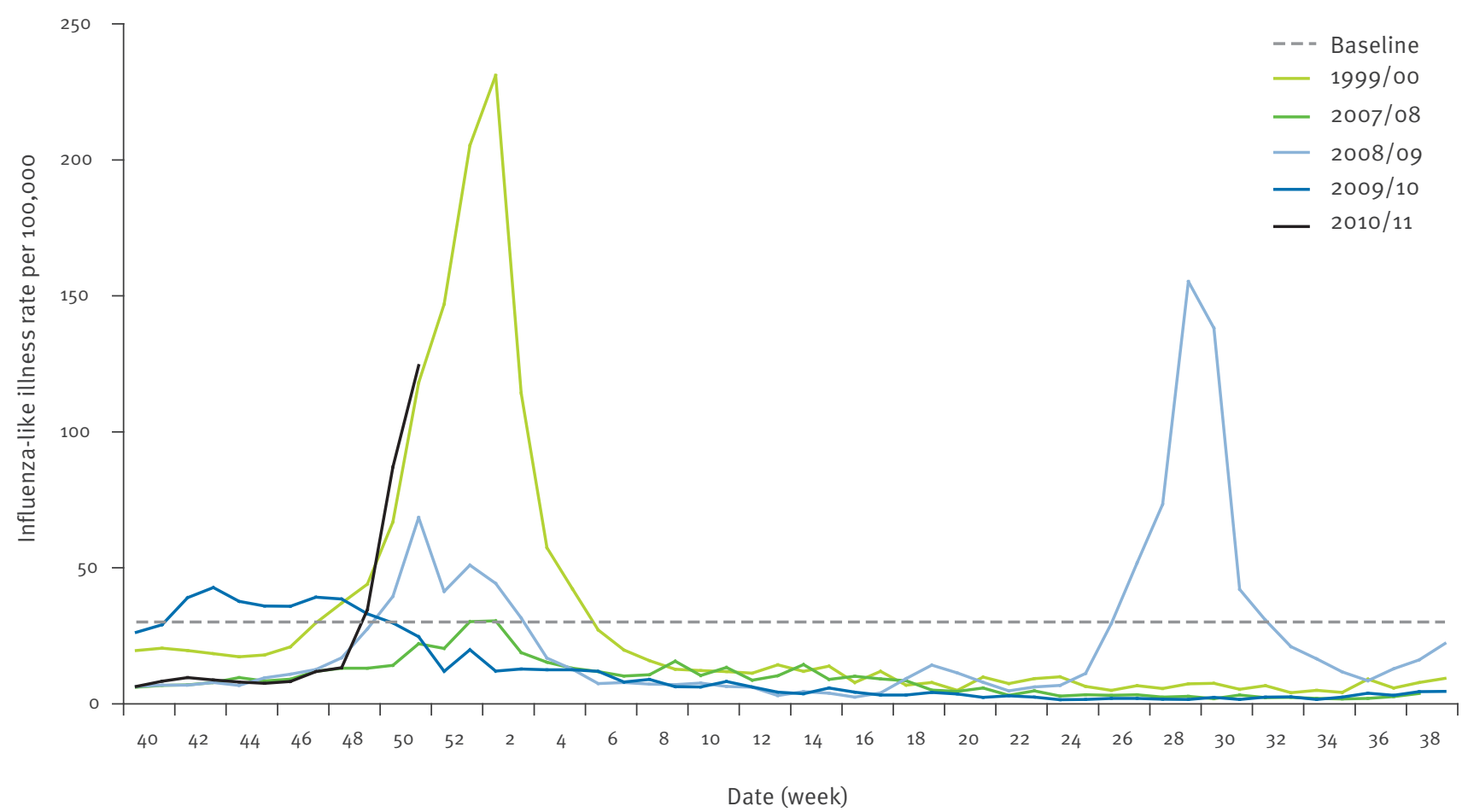


probability of extensive morbidity in this age group associated with this strain in winter 2010/11 was considered unlikely in the absence of significant antigenic change in the pandemic virus. The extent, however, to which influenza $A\left(\mathrm{H}_{1} \mathrm{~N}_{1}\right) 2009$ would predominate over influenza $A\left(\mathrm{H}_{3} \mathrm{~N}_{2}\right)$ and cause illness in the remaining susceptible children and younger adults was unknown.

\section{Investigations}

Virological surveillance in the UK operates through hospital laboratories in secondary care and community-based schemes. Specimens containing influenza virus from community, hospitalised and fatal cases are forwarded to the UK National Influenza Centre for further characterisation. Samples are also received directly from sentinel primary care physicians participating in virological surveillance schemes in the community [5]. An antigenic typing profile is developed for each virus isolate and compared with influenza vaccine and reference strains. Genotypic and, where appropriate, phenotypic antiviral susceptibility analyses are performed on influenza-positive clinical material and/

\section{FIGURE 2}

Influenza positivity rates from community sentinel virological surveillance in England by age, 4 October-26 December 2010

\section{A. influenza $A\left(\mathrm{H}_{1} \mathrm{~N}_{1}\right) 2009$}

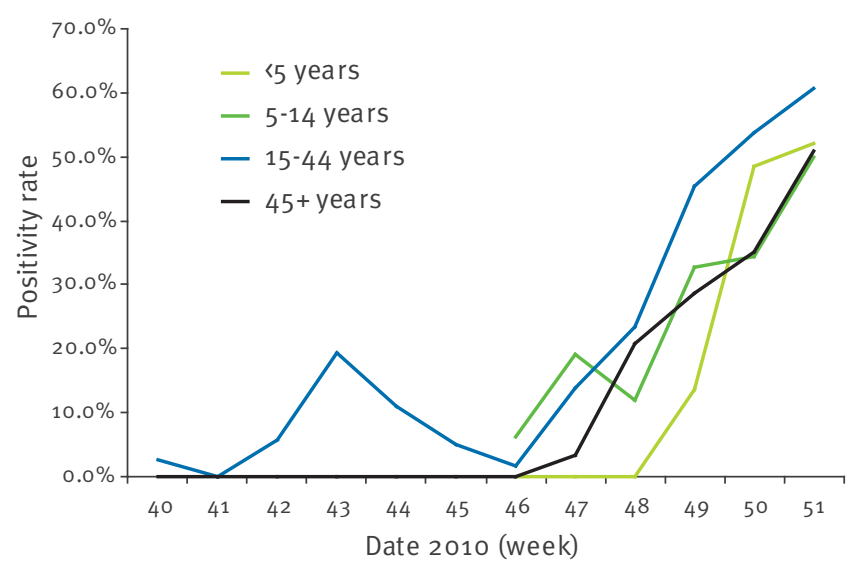

B. Influenza B

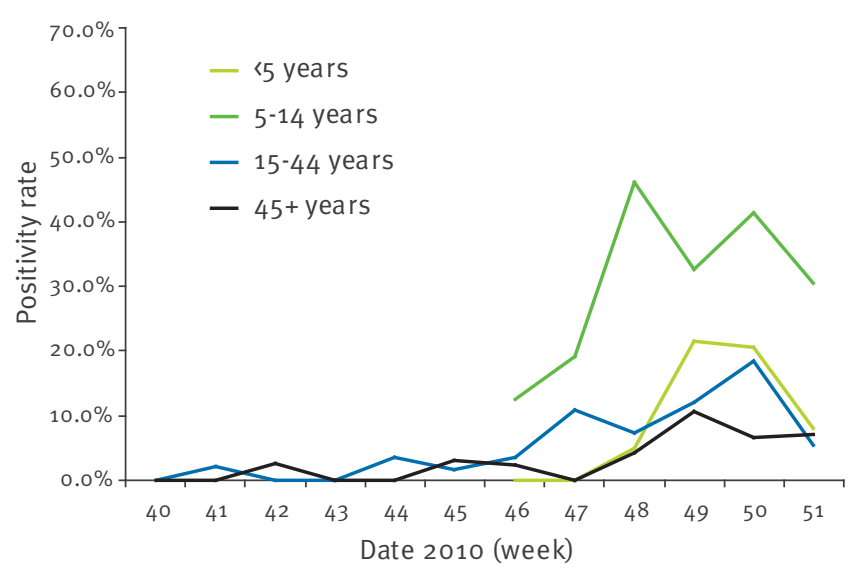

Rates with sample number less than 10 are not presented. Recent weeks' data may not be complete due to reporting time lag. or virus isolates. Genetic characterisation is performed by targeted haemagglutinin ( $\mathrm{HA}$ ) sequence analysis and/or whole genome sequencing for a subset of isolates (primer sequences available on request).

We describe here observations undertaken as part of routine national surveillance. These are carried out under National Health Service (NHS) Act 2006 (section 251), which provides statutory support for disclosure of such data by the NHS, and their processing by the Health Protection Agency (HPA) for communicable disease control [6].

\section{Epidemiological findings}

Early detections of influenza $A\left(\mathrm{H}_{1} \mathrm{~N}_{1}\right)_{2009}$ virus were first reported in weeks 40-42 from cases in the community. Indicators of clinical activity began to rise in week 47 crossing the traditional baseline threshold level indicating generalised influenza activity in the community in week 49, and have continued to increase up to week 52 (Figure 1).

Influenza $A\left(\mathrm{H}_{1} \mathrm{~N}_{1}\right) 2009$ viruses, followed by influenza $B$, have been the predominant influenza viruses circulating in the community in the period from October to the end of December 2010. Of 3,959 respiratory specimens reported to the English Data Mart system as taken in week $51,1,711$ (43.2\%, increased from $38.9 \%$ in week 50) were positive for influenza, namely 1,402 influenza $A\left(\mathrm{H}_{1} \mathrm{~N}_{1}\right) 2009,41$ not subtyped influenza $A$ and 268 influenza B [7]. Since the beginning of the season, over 120 institutional outbreaks of respiratory illness have been reported, primarily from schools: 112 (93\%) outbreaks from schools, four from care homes, two from hospitals, one from a military base, one from a nursery and two from prisons. Both influenza $B$ and influenza $A\left(\mathrm{H}_{1} \mathrm{~N}_{1}\right)_{2009}$ have been detected in the few outbreaks that have been virologically investigated and confirmed: 22 outbreaks (44\%) with influenza $A\left(\mathrm{H}_{1} \mathrm{~N}_{1}\right) 2009$ detected, 16 with influenza $B$, four with a mixture of influenza $A\left(\mathrm{H}_{1} \mathrm{~N}_{1}\right) 2009$ and influenza $B$, one with influenza $A\left(\mathrm{H}_{3} \mathrm{~N}_{2}\right)$ and seven with other respiratory viruses.

Admissions to hospital with severe illness have been reported. As of 30 December 2010, there were 738 patients with confirmed or suspected influenza in NHS critical care beds in England (42 cases under five years of age, 24 cases between five and 15 years, 586 cases between 16 and 64 years, and 86 cases 65 years and above) [8]. Thirty-nine deaths were reported between weeks 36 and 52 associated with confirmed influenza infection [7]. Four of the fatal cases were under five years of age, seven were 5-14 years of age, 27 cases were 15-64 years of age, and one fatal case was older than 64 years. The majority (36/39) of these deaths were associated with influenza $A\left(\mathrm{H}_{1} \mathrm{~N}_{1}\right)_{2009}$ infection, and three with influenza $B$ infection. Underlying chronic conditions were reported in 23 of the 38 fatal cases for whom this information was available, with neurological disease such as cerebral palsy $(n=9)$ and asthma 


\section{FIGURE 3}

Phylogenetic relationship of full-length HA sequences of influenza A(H1N1)2009 viruses from fatal, severe and mild cases in the United Kingdom during 2010

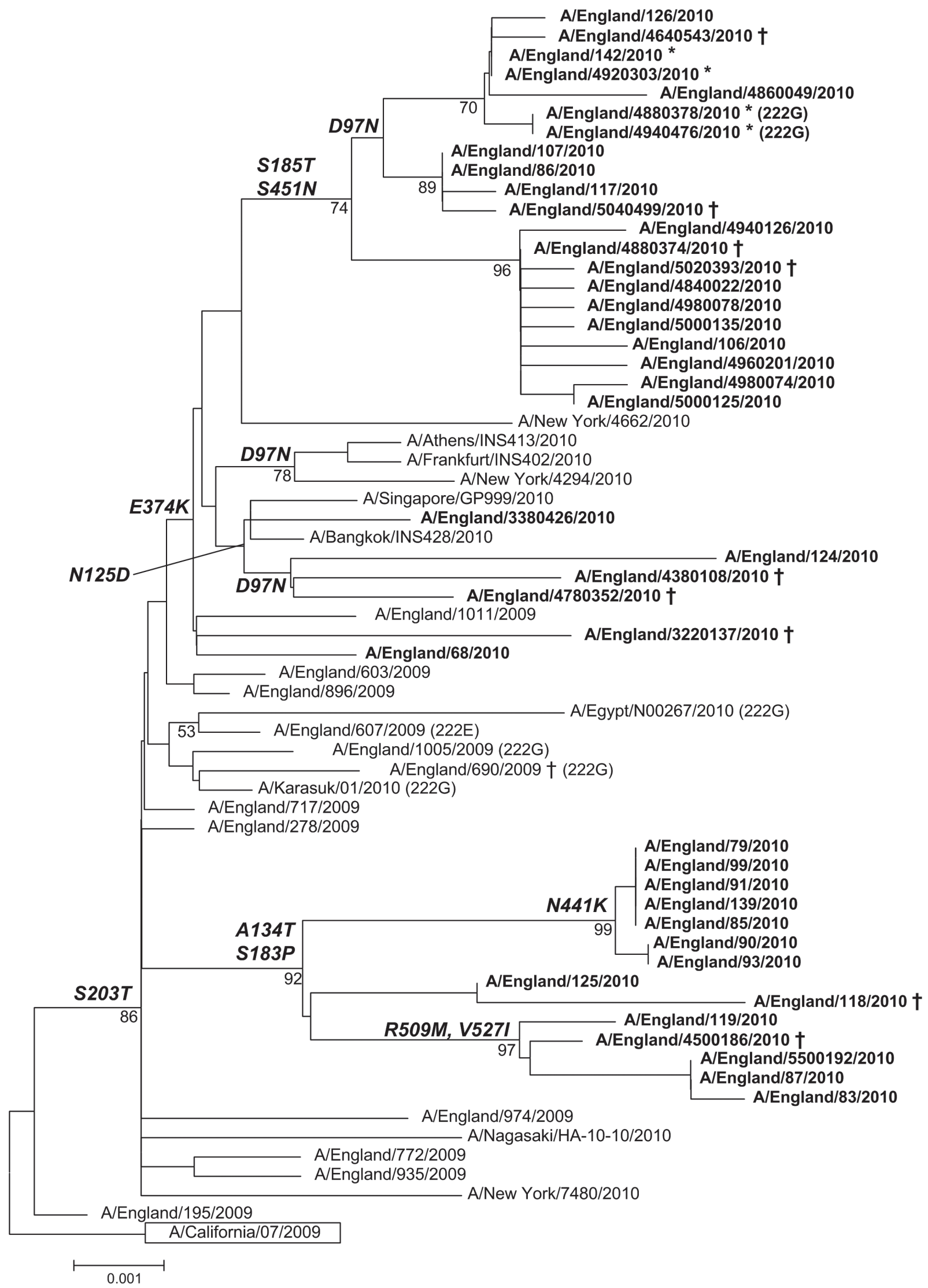

HA: haemagglutinin.

† Fatal case; * severe case.

Sequences downloaded from the NCBI Influenza Virus Resource (http://www.ncbi.nlm.nih.gov/genomes/FLU/) representative of globally circulating viruses during 2010 and, in bold, UK sequences from the first and second pandemic wave of 2009 were included. The tree was rooted with the vaccine strain A/California/07/2009 (boxed) as outgroup. Branch lengths are drawn to scale. Signature amino acid changes ( $\mathrm{H}_{1}$ numbering) are annotated at the nodes of each cluster. Viruses with $222 \mathrm{G}$ or $222 \mathrm{E}$ changes are marked in the tree. 


\section{FIGURE 4}

Phylogenetic relationship of HA1 sequences of influenza B viruses from fatal and mild cases in the United Kingdom during 2010

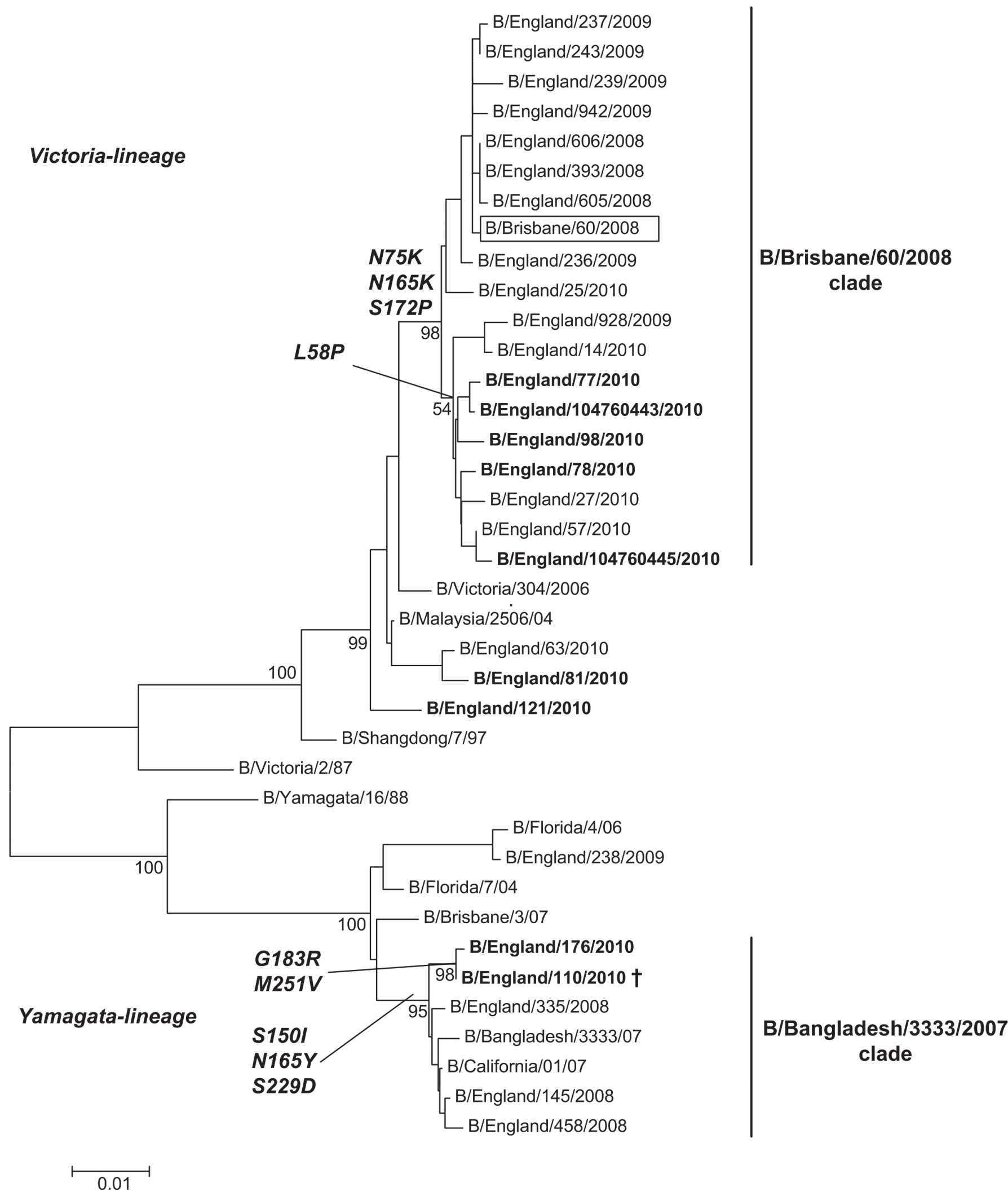

HA: haemagglutinin.

$\uparrow$ Fatal case.

Branch lengths are drawn to scale. Amino acid changes characteristic of clades are marked in the tree. Sequences from UK 2010 viruses are in bold, and the $2010 / 11$ vaccine strain is boxed. 
$(n=8)$ the most frequently reported underlying risk factors for vaccination [9]. Very few of the fatal cases (2/33) had received the $2010 / 11$ trivalent influenza vaccine. A third of the cases $(8 / 22)$ had not received antiviral therapy.

The proportion of samples from patients with influenza-like illness in sentinel general practitioner surveillance schemes in the community reported positive for influenza virus $\left(A\left(\mathrm{H}_{1} \mathrm{~N}_{1}\right)_{2009}\right.$ or $\left.B\right)$ has risen rapidly to over $50 \%$ in week 49 . The proportion of samples positive for influenza $\mathrm{A}\left(\mathrm{H}_{1} \mathrm{~N}_{1}\right) 2009$ virus was highest in young adults (15-44 years), and for influenza B in children aged 5-14 years (Figure 2).

By week 50, the proportion of the population in England aged under 65 years in a risk group who had received the $2010 / 11$ influenza vaccine was $43 \%$ [7].

\section{Virological investigations}

Influenza $\mathrm{A}\left(\mathrm{H}_{1} \mathrm{~N}_{1}\right) 2009$ isolates characterised to date, in samples from the community, hospitalised patients and fatal cases, are antigenically homogeneous and similar to the $A\left(H_{1} N_{1}\right)_{2009}$ virus included in the $2010 / 11$ seasonal influenza vaccine, A/California/7/2009. Only minor genetic drift has been noted in influenza $\mathrm{A}\left(\mathrm{H}_{1} \mathrm{~N}_{1}\right) 2009$ viruses circulating in 2010 compared with the earliest isolates in April 2009, and this observed genetic diversity has been consistent with expected patterns of virus evolution (Figure 3). Phylogenetic analysis shows that HA sequences from nine fatal and four severe cases in the UK in 2010 were interspersed with sequences from mild cases in 2010 from the UK and elsewhere. All UK 2010 viruses cluster in two main branches, characterised by either E374K with additional mutations in minor subclusters such as D97N, S185T, S451N and N125D, some of which have been recently described [10], or by $\mathrm{A}_{134} \mathrm{~T}$ and $\mathrm{S} 183 \mathrm{P}$, with additional substitutions such as N441K, R509M and V527l. Almost all viruses from winter 2010 analysed to date from fatal and non-fatal cases had 222D in the HA gene (39/41).

Preliminary analyses from a limited number of whole genome sequences including some from fatal cases, indicate that these are consistent with observations from seasonal influenza and from the first and second waves of the recent pandemic: so far no unique mutations have been associated with severe or fatal cases of influenza $A\left(\mathrm{H}_{1} \mathrm{~N}_{1}\right)_{2009}$, but further comprehensive analysis is required.

Between October and December 2010, antiviral resistance monitoring was undertaken on 156 community and 159 hospital isolates. Six cases of oseltamivir resistance associated with the $\mathrm{H}_{275} \mathrm{Y}$ mutation in the neuraminidase (NA) gene have been detected.Only one of these cases has had known exposure to oseltamivir, Two of them have been identified from community surveillance of uncomplicated infections, three cases have been detected before treatment in individuals hospitalised with underlying risk factors, and the sixth case has been detected after oseltamivir treatment in a hospitalised individual.

Over $98 \%$ of influenza B viruses isolated in the UK since week 40 in 2010 have been from the $B /$ Victoria/2/87 lineage, with most showing good reactivity to antisera raised against reference viruses from this lineage. The HA sequences group within the genetic clade represented by the current vaccine strain, B/Brisbane/60/2008, characterised by amino acid substitutions L58P N75K, N165K and S172P (Figure 4). A separate small cluster of three viruses from the antigenically distinct $\mathrm{B} /$ Yamagata/16/88 lineage have also been detected in one region of England: one fatal case and two hospitalised cases. The three known fatal influenza B cases were distributed across both lineages. The HA segment of the influenza B/Yamagata lineage virus isolated from a fatal case in week 46 belonged to a clade represented by influenza $B /$ Bangladesh/3333/2007, with amino acid substitutions S150l, N165Y and S229D relative to a previous vaccine strain, B/Florida/4/06. This HA sequence contained two additional substitutions, $\mathrm{G}_{18} \mathrm{R}$ and $\mathrm{M}_{251 \mathrm{~V}}$, which had been sporadically detected in influenza $B$ viruses isolated in several countries in 2009/10.

Antigenic characterisation of the few influenza $\mathrm{A}\left(\mathrm{H}_{3} \mathrm{~N}_{2}\right)$ viruses detected since week 38 indicates that these viruses are closely related to $A / P e r t h / 16 / 2009$, the influenza $A\left(\mathrm{H}_{3} \mathrm{~N}_{2}\right)$ 2010/11 vaccine strain.

\section{Conclusions}

Influenza virus circulation is underway in the UK and is contributing to seasonal winter pressures in the health system. The circulation of other winter viruses such as respiratory syncytial virus (RSV) and the particularly cold weather are also contributing. The virological picture is complex, with many strains of influenza virus circulating but no antigenic change in the influenza $A\left(\mathrm{H}_{1} \mathrm{~N}_{1}\right) 2009$ virus, and no immediately obvious genetic differences between viruses recovered from fatal cases and those causing mild illness. The picture of the illness associated with influenza $A\left(\mathrm{H}_{1} \mathrm{~N}_{1}\right) 2009$ infection is consistent with what was seen in the 2009 pandemic, with a similar demographic impact, particularly affecting children and young adults. Whilst young age groups have the least experience of influenza and are recognised as important in the transmission of influenza, it is also possible that propensity to consult a doctor is greatest in younger age groups. Although the remaining susceptibles in the age group under 15 year account for high rates of positivity in peak weeks in community samples (as is often the case during seasonal influenza), it is notable that overall, sustained high rates of positivity are most marked in the age group between 15 and 44 years. This is in contrast to earlier pandemic waves in 2009 when highest rates of positivity in the community were observed in the 5-14 year-olds. The age group of $15-44$ year-olds is also clearly the major group contributing to hospital admissions and deaths. The increase in requirement for 
critical care in the current season reflects the impact of influenza $A\left(\mathrm{H}_{1} \mathrm{~N}_{1}\right)_{2009}$ illness in the remaining susceptible young adults (15-44 years) and risk groups in the population.

Most of those with severe illness, and those dying, have not previously been vaccinated against influenza and have not had the benefit of the early use of antiviral drugs. Countries in Europe yet to experience substantial influenza activity this winter may wish to take all reasonable measures to increase the uptake of seasonal influenza vaccine in those at high risk of the complications of influenza and to ensure that antiviral drugs are readily available for those who are either severely ill or at increased risk of severe illness from influenza.

Further analysis of the antigenic and genetic properties of all influenza viruses from hospitalised patients, outbreaks and community cases is ongoing.

\section{Acknowledgements}

The authors would like to acknowledge the contribution of the member laboratories of the Microbiology Services Division Laboratory Network, HPA, and participating RCGP practices, in submitting the clinical samples evaluated in this study. Technical and data support was provided by Richard Allan and the Respiratory Virus Unit, Microbiology Services: Colindale, Nichola Goddard, Microbiology Services: Colindale, Genomic Services Unit-AFGU, Department for Bioanalysis and Horizon Technologies, Microbiology Services: Colindale, and Respiratory Virus Department, Health Protection Services, Colindale, HPA. Thank you to John McCauley and Rod Daniels, WHO Collaborating Centre, UK, for useful discussions.

\section{References}

1. Influenza Update 117. Geneva: World Health Organization; 24 September 2010. Available from: http://www.who.int/csr/ disease/influenza/2010 09 24 GIP surveillance/en/index. html

2. Epidemiological report of pandemic $\left(\mathrm{H}_{1} \mathrm{~N}_{1}\right) 2009$ in the UK. London: Health Protection Agency; October 2010. Available from: http://www.hpa.org.uk/Publications/InfectiousDiseases/ Influenza/1010EpidemiologicalreportofpandemicH1N12009in UK/

3. Hardelid P, Andrews NJ, Hoschler K, Stanford E, Baguelin M, Waight PA, et al. Assessment of baseline age-specific antibody prevalence and incidence of infection to novel influenza $\mathrm{AH}_{1} \mathrm{~N}_{1}$ 2009. Health Technology Assessment. 2010; 14(55): 115-92.

4. Ghani AC, Baguelin M, Griffin J, Flasche S, Pebody R, van Hoek Al, et al. The early transmission dynamics of $\mathrm{H}_{1} \mathrm{~N}_{1}$ pdm influenza in the United Kingdom. PLoS Curr. 2009 Nov $16 ; 1:$ RRN1130.

5. Fleming DM, Chakraverty P, Sadler C, Litton P. Combined clinical and virological surveillance of influenza in winters of 1992 and 1993-4. BMJ. 1995:311(7000):290-1.

6. The National Health Service Act 2006, The National Health Service (Wales) Act 2006 and The National Health Service (Consequential Provisions) Act 2006. London: Department of Health; 21 December 2010. Available from: http://www.dh.gov. uk/en/Publicationsandstatistics/Legislation/Actsandbills/ DH_064103

7. HPA Weekly National Influenza Report; Summary of UK surveillance of influenza and other seasonal respiratory illnesses- Week 52. London: Health Protection Agency; 30 December 2010. Available from: http://www.hpa.org.uk/web/ HPAwebFile/HPAweb_C/1287147913387
8. Winterwatch. Winter health data. London: Department of Health; 30 December 2010. Available from: http://winterwatch. dh.gov.uk/winter-health-data-31-december-2010/

9. Influenza. In: Immunisation against infection disease - 'The Green Book'. London: Department of Health; 24 December 2010. Available from: http://www.dh.gov.uk/prod_consum_dh/ groups/dh_digitalassets/documents/digitalasset/dh_123162. pdf

10. Barr IG, Cui L, Komadina N, Lee RT, Lin RT, Deng Y, et al. A new pandemic influenza $A\left(\mathrm{H}_{1} \mathrm{~N}_{1}\right)$ genetic variant predominated in the winter 2010 influenza season in Australia, New Zealand and Singapore. Euro Surveill. 2010;15(42):pii=19692.

Available from: http://www.eurosurveillance.org/ViewArticle. aspx?Articleld $=19692$ 